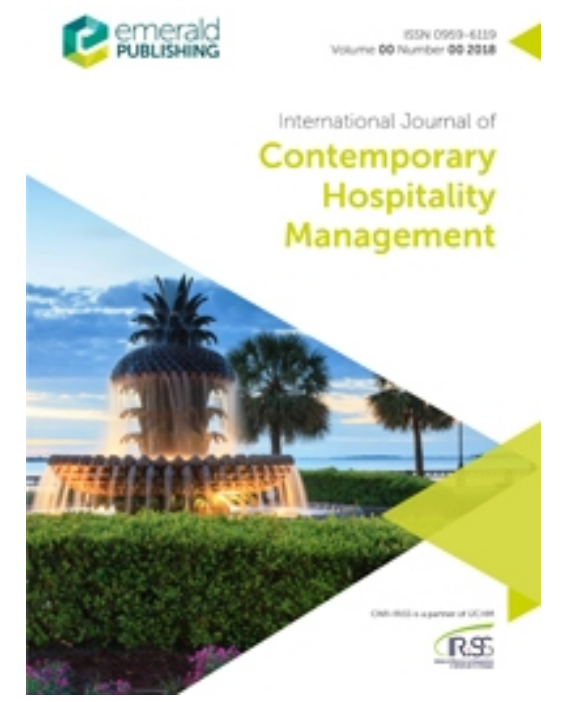

\title{
Positive power: Events as temporary sites of power which "empower" marginalised groups
}

\begin{tabular}{|r|l|}
\hline Journal: & International Journal of Contemporary Hospitality Management \\
\hline Manuscript ID & IJCHM-08-2020-0935.R3 \\
\hline Manuscript Type: & Original Article \\
\hline Keywords: & $\begin{array}{l}\text { Marginalised groups, critical event studies, social-structural } \\
\text { empowerment, psychological empowerment, community participation, } \\
\text { social capital }\end{array}$ \\
\hline \multicolumn{2}{|l}{} \\
\hline
\end{tabular}

\section{SCHOLARONE ${ }^{\text {M }}$ Manuscripts}




\title{
Positive power: Events as temporary sites of power which "empower" marginalised groups
}

\begin{abstract}
Purpose: The importance of events for marginalised groups has largely been overlooked within tourism, hospitality and event studies. The purpose of this international study is to address this gap, emphasising the positive outcomes of power relationships rather than the negative, which have traditionally been the focus in event studies.
\end{abstract}

Approach: The study investigated eight events for indigenous and ethnic minority groups, rural women, disabled people and seniors in Australia and New Zealand. Qualitative data was collected via participant observation, reflexive ethnography, semi-structured interviews and inthe-moment conversations. An inductive thematic approach was taken to data analysis.

Findings: Eight themes around notions of power and empowerment were identified during the analysis: providing a platform, giving/taking ownership, gaining confidence, empowering with/through knowledge, respect, pride and affirmation, freedom to 'be', and resistance. These were then viewed through the lenses of social-structural and psychological empowerment, enabling a deeper understanding of power at/through events.

Implications: The paper presents a framework for empowerment that enables event organisers to both understand and deliberately plan for the productive use of power, which can reaffirm important event aims, objectives and values. It can also be used by researchers as a framework through which to identify and assess the contributing elements of empowerment at events, and by local government to guide policymaking around events.

Originality/value: This study is the first to highlight best practices for the positive use of power at events that 'empowers' marginalised groups. Grounded in empowerment theory, the study offers a new lens to reframe notions of power and provides a theoretical framework that will be of value for both critical event studies researchers, event organisers and policymakers alike.

Keywords: Marginalised groups, critical event studies, social-structural empowerment, psychological empowerment, community participation, social capital, festivals 


\section{Introduction}

The locus of power is located at the 'centre' and the expression of power therefore determines who lies 'at the margins' (Smith and Pitts, 2007). Groups and communities may be marginalised for several reasons, including race, gender, religion, sexuality, age, refugee/migrant status, socio-economic status or geographic location. This frequently results in their being subject to threats, derision, discrimination and exploitation, and being treated as objects rather than people (Kauff et al., 2017; Smith and Pitts, 2007). The subsequent sense of powerlessness can have significant implications across all areas of life - social, economic, health and wellbeing (both physical and mental) and cultural.

In recent years power has become a much-debated topic in the event studies literature (a seminal work is Jepson and Clarke's (2018) edited book Power, construction and meaning in festivals which has contributions from many countries and types of events). All event stakeholder relationships are shaped and influenced by power; power that is based on the level of each stakeholder's interest in the event, their financial resources, resource ownership, and their influence in terms of decision-making (Reid, 2011). These power relationships in turn shape the way events are constructed, planned and delivered, as well as their impact on attendees and other event consumers (Jepson and Clarke, 2014). To date, scholars have focused on the negative outcomes of power relationships (see for example Batty 2016; Clarke and Jepson 2011; Tiew et al., 2015) and have largely overlooked the experiences of marginalised groups. While two recent studies investigating events for ethnic minority migrants have identified the psychological benefits of such events, and noted a feeling of empowerment, they used theories of counterspace and 'psychological sense of community' respectively, rather than power dynamics (Hassanli et al., 2019, 2020).

This international study addresses these gaps, examining positive outcomes of power at eight events in, by and for a wide variety of marginalised groups. It is theoretically grounded in conceptualisations of empowerment (Spreitzer, 2008), community participation (Arnstein, 1969) and social capital (Taylor, 2011). The paper culminates in a framework for empowerment that enables event organisers to both understand and deliberately plan for the productive use of power. This can also be used by researchers as a theoretical framework through which to assess empowerment at/through events, and by local government to guide policymaking around events. The paper therefore addresses a contemporary issue, makes a 
meaningful contribution to the field of critical event studies, and has applicability for scholars and practitioners alike.

\section{Conceptual background}

\section{Traditional conceptualisations of power in events research: a brief overview}

Events research has been dominated by traditional management conceptualisations of power as a resource which can be used to influence, or in extreme cases coerce, other people to achieve a certain goal. Power is used by one actor 'over' another and as one gains more power, another automatically loses their power. Power can also take on different forms: reward power, coercive power, group power, or the types of power sometimes exercised by event organisers such as legitimate power, expert power, or information power (Benfari et al., 1986; Buchanan and Badham, 2020).

This concept of power as a resource to use over others has been applied to events in recent years: Clarke and Jepson (2011), for example, investigated the use of power as a source of discipline and control throughout the decision-making process around a community festival in Derby, UK. Similarly, Batty (2016) identified examples of stakeholders' legitimate power due to their position within community sports event organisations in New Zealand. Positions of power may be perceived differently, however; while event organisers may perceive a certain stakeholder group to have a lot of power, these stakeholders do not necessarily share this view. White and Stadler (2018), for instance, found that the UK's Glastonbury Festival claims to engage and involve the local community through giving back to them (e.g. free tickets). The community, though, feel rather powerless regarding the decisions made about the festival and their involvement in it.

\section{Conceptualising positive power and empowerment in an events context}

We seek to put forward the alternative notion of 'positive power' for consideration. Instead of regarding power as a resource 'over' somebody, power can also be seen as a capacity to 'do' something (Lukes, 1974; Taylor, 2011). Power can be created through relationships between stakeholders, where each stakeholder is just one actor within this network of relations. In this sense, power produces new things; it cannot be given to one person or one stakeholder, it cannot be regained, but rather it is exercised; it operates at all different levels of the social body, and as such it constantly changes (Foucault, 1982). 
Knowledge has been identified as one such source of power. However, more knowledge does not necessarily mean more power, because neither can be possessed (Foucault, 1980). Rather, power/knowledge is embedded within social relationships between people, groups, stakeholders and organisations. The idea of power/knowledge relations has been applied to a festival case study by Stadler (2013), which highlighted the positive use of both power and knowledge between the festival organisers and the community: through engaging the community as equal partners throughout the creative process and by making their voices heard, the community felt empowered. At the same time, festival organisers gained new knowledge they had to change their ways of thinking and working with the community and empowering them, rather than imposing their own ideas upon them.

The power balance between actors can therefore be changed in a positive way. In relation to marginalised communities, the subject of this paper, Walters and Jepson (2019) recently argued that events can help overcome marginalisation through the taking back of power, through reshaping power relations to give communities the capacity to (albeit temporarily) take control of their circumstances, make their voices heard and achieve their own goals. However, the power of the privileged means marginalised communities are often misunderstood, underrepresented or excluded from an event altogether. It is therefore important to acknowledge that event organisers can, whether deliberately or not, use power relationships to adopt either inclusionary or exclusionary approaches to event planning and management, and hence can turn power into a form of resistance on the one hand, or transformation on the other.

\section{Empowerment}

The concept of empowerment has been much debated within organisational and management literature, with two key perspectives emerging: social-structural empowerment and psychological empowerment (Spreitzer, 2008). The first focuses on the contextual conditions in the workplace which enable empowerment for employees, while the second highlights individual employees' psychological experience(s) at work, and both complement and reinforce each other.

Social-structural empowerment includes having the power to make decisions for the organisation where it is relevant to one's job or role, as well as having authority and control over organisational resources (Lawler, 1986). The aim is to share power through the delegation of responsibility across all levels of the organisation. It can be achieved through the 
implementation of organisational policies, structures and practices that give all employees access to opportunity, information, support and resources. According to Spreitzer (2008), social-structural empowerment manifests itself in practices such as participative decisionmaking, skill and/or knowledge-based pay, open flow of information, flat organisational structures, and training. In an event organisation, open flow of information, for example, is important not only from permanent staff members down to volunteers (e.g. clear goals, tasks and expectations), but also the flow of information from volunteers back up (e.g. suggestions for improvement based on their front-line experience) (Stadler, 2021). Equally as important is participative decision-making, which has also been identified as a key organisational practice in events when working with communities and engaging them in the event planning process (Clarke and Jepson, 2011; Rogers and Anastasiadou, 2011; White and Stadler, 2018).

Psychological empowerment is "a set of psychological states that are necessary for individuals to feel a sense of control in relation to their work" (Spreitzer, 2008, p.56). In an organisational context, it is based on how employees perceive and experience their work, their personal beliefs about their role, as well as their sense of self-efficacy (Conger and Kanungo, 1988). In order for employees to truly feel empowered, four psychological states need to be experienced: (1) Meaning: employees get a sense of meaning from their job if it fits with their career goals, personal beliefs and values; (2) Competence: the belief that one is capable of performing the job with skill and knowledge; (3) Sense of self-determination/autonomy: having the freedom, autonomy and independence to make decisions about which tasks to engage in to perform the job; and (4) Impact: the degree to which an employee perceives their decisions to have an impact on administrative, strategic and operational outcomes (Spreitzer, 1997, 2008).

\section{Community participation and empowerment}

At the community level of empowerment, we further draw on Arnstein's (1969) ladder of citizen participation (Figure 1): the first two rungs on the ladder result in non-participation, rungs 3-5 correspond to different levels of tokenism, and the top three rungs denote increasing degrees of citizen power.

\section{INSERT FIGURE 1 HERE}

At a community level and in the context of community participation and community engagement, Cole (2006, p.97) refers to this in her definition of empowerment as, 
"the capacity of individuals or groups to determine their own affairs. It is a process to help people to exert control over factors that affect their lives. It represents the top end of the participation ladder where members of a community are active agents of change and they have the ability to find solutions to their problems, make decisions, implement actions and evaluate their solutions."

We argue that events can thus be considered 'sites of power' (Westwood, 2002, p.135) and can be the catalyst for this positive change in power to happen through working at the top rungs of the participation ladder.

As with the two dimensions of empowerment discussed above, empowerment through events can also happen at two different levels. Firstly, at the organisational level, in the sense that event organisers and volunteers can be empowered to do their job and make effective decisions. Secondly, at the community level where the purpose of the event is to empower a marginalised community, make their voices heard, and hence for the community to take ownership of the event. These two levels of empowerment need to reinforce each other, in order to create an empowering event overall. For example, empowerment at the organisational level can include creating partnerships with the community and including them in the decision-making process, rather than imposing ideas and exercising power 'over' them. This in turn can enhance empowerment at the community level through the community feeling a sense of pride and a sense of ownership of the event (Kay, 2000; Stadler, 2013).

At a community level, Taylor (2011) argues that communities can more specifically be empowered through a capacity development approach based on developing the skills, assets and capacities already available within a community. By redressing inequalities and providing opportunities for learning, networking and organising, communities can recognise and mobilise those capacities that are important to them, and in turn achieve a sense of empowerment. The necessary infrastructure and institutional support need to be in place in order to create a platform for communities to develop these capacities, but it is the inclusion of communities' voices that form the basis for empowerment, as the entire process needs to be grounded in the community's own concerns rather than imposed from outside.

A further important outcome of the process of capacity development is the creation and enhancement of social capital within the community. Arcodia and Whitford (2007) argued that events can enhance social capital through developing community resources, promoting social cohesiveness, developing a common social purpose (giving the community a 'voice'), and 
through celebration. Wilks (2011) on the other hand, found the festivals in her study provided opportunities for bonding social capital to develop through shared values and mutual trust between attendees, but the formation of bridging social capital - new social connections with previously unconnected attendees - was not achieved through festival attendance. A third type of social capital has the potential to be important for marginalised communities: linking social capital, defined as,

"connections with people in positions of power and is characterised by relations between those within a hierarchy where there are differing levels of power (...). It is different from bonding and bridging in that it is concerned with relations between people who are not on an equal footing." (Taylor, 2011, p.55)

While bridging social capital is commonly argued to be important in terms of developing social cohesion, it is linking social capital that addresses issues of power and empowerment. Through it, communities can become equal partners, empowered producers and co-producers, as well as empowered citizens on a broader scale (Taylor, 2011). Both capacity and social capital development are therefore essential components in the process of empowerment at the community level.

\section{Research context}

Events selected for this research project include those for indigenous and ethnic minority groups, low socio-economic communities, rural women, disabled people and seniors (over 50s) in Australia and New Zealand. These are groups that are commonly marginalised, facing varying levels of explicit and/or implicit discrimination due to their ethnicity, income, ability, age, gender and/or geographic location (Walters and Jepson, 2019). Seven of the events are from across New Zealand and two are from Queensland, Australia (Table 1) and they are introduced below.

\section{INSERT TABLE 1 HERE}

\section{Clutha Market and Trade Expo (formerly Clutha Women in Business Expo)}

The Women in Business Expo is held in the Clutha District of southern New Zealand, a rural region with a population of just under 17,000 people, and approximately 90 minutes south of Dunedin city by car. It is a free annual business event (although stallholders pay a nominal fee) 
organised by the Clutha Women in Business Network (formed in early 2017) and was first held in the region's main town of Balclutha in September 2017. The region has experienced population decline of 7 percent since 1991 (Stats NZ, 1996, 2013a), and experiences a number of other challenges common to rural communities such as poor infrastructure (e.g. slow broadband, limited banking facilities), over-reliance on primary industry, an ageing population and rising unemployment (Bock, 2016; Siemens, 2010).

\section{Leisure Marching Nationals}

Marching is a competitive team sport for girls and young women that originated in New Zealand in the late 1930s and remained popular as an outdoor summer sport until the late 20th century (Macdonald, 2011). Leisure marching, a non-competitive version of the sport, began in 1991 with a group of six women over the age of 50 who decided to form a marching team for the purpose of 'exercise, fun and friendship' rather than competition (Leisure Marching New Zealand, 2017). There is no longer an informal minimum age for participation and in 2017 there were over 1000 "mature ladies" marching in 110 teams across New Zealand. The annual Leisure Marching Nationals event is held in locations alternating between the North and South Islands and is organised as a fundraising exercise by one or more teams from that location.

\section{Pasifika Festival}

The Wellington Pasifika Festival, held in New Zealand's capital city, began in 2006 and now attracts over 15,000 people each year. The free admission one-day festival highlights the arts, culture and food of the city's many distinctively different but tight-knit Pasifika communities, and takes place in a public square in the central city area. In addition to performances by traditional and modern Pasifika artists and music groups, attendees can purchase Pacific food and handicrafts, engage in free activities such as hula sessions and tapa cloth printing, and meet Pasifika representatives from political and other public sector organisations (Wellington City Council, 2019).

\section{Diwali Festival of Light}

Invercargill is a small regional city of approximately 51,700 people located in the far south of the South Island of New Zealand. The population is largely white and less diverse than the country as a whole, but the Asian population has more than doubled since the 2006 census 
(Stats NZ, 2018). The Indian Community in Southland (ICS) is an incorporated society formed in mid-2018 to provide support and activities for the growing Indian population in Invercargill. In late 2018 it organised the first Diwali Festival of Light in the city, a free event which approximately 3,000 people attended. Diwali (also known as Deepavali) is of special significance to Hindus, but is also celebrated by Indians from other religions, and symbolises the victory of light over darkness, good over evil and the renewal of life (Satyanand, 2007).

\section{InterACT Disability Arts Festival}

The InterACT Disability Arts Festival was established in Auckland in 2011 and is a free event that celebrates the achievements of disabled people in the arts. Held in a large warehouse over three days each October, it incorporates live music, theatre performances, wearable arts parades, an art exhibition and creative workshops (InterACTing Theatre Company, 2019). In 2019 the festival attracted approximately 4,000 people from all parts of the city, ranging in age from primary school to retired and a wide range of abilities.

\section{South Dunedin Street Festival}

South Dunedin is a marginalised suburb in Dunedin city, with its population of just under 2500 being more culturally diverse, older, less educated, with more disability, higher unemployment and twice the number of single parent families, and lower levels of income, car and home ownership, and access to technology than the city as a whole (Stats NZ, 2013b). The first South Dunedin Street Festival was held in 2011 and regularly attracts over 5,000 attendees. The celebration aims to build a stronger sense of community and showcase the resilience of its residents in the face of local government neglect (Walters, 2019). The main street is closed to traffic, stages are set up for performances and a wide variety of stallholders (including local food vendors, shops, charities and social services) offer food, crafts, goods, services and information to attendees.

\section{Behind the Cane}

Behind the Cane was a community cultural development project commissioned and presented by the Queensland Music Festival in 2011. It was organised over a three-year period through collaboration between the festival organisation, the regional council and the South Sea Islander community in Bowen, Queensland, Australia. Behind the Cane told the history of thousands of 
South Sea Islanders being kidnapped ('blackbirded') and brought to Queensland to work on sugar cane farms between 1863 and 1906. Cast members were all descendants from South Sea Islanders, representing their own family members on stage. The free performance was presented at the Bowen Soundshell over three nights, with approximately 120 cast members and a total audience of about 8,000 (QMF, 2011).

\section{Drag Queen'sLand}

Drag Queen'sLand was another community project commissioned and presented by the Queensland Music Festival in 2011. It was a theatrical work about challenges of being a drag queen in Queensland (a state with a historically hostile relationship with the queer community). The ticketed show was presented at the Judith Wright Centre in Brisbane, and was an 18+ event containing "violence, adult themes, nudity, offensive language and theatrical smoke effects" (QMF brochure, 2011). All seven shows were sold out with a total audience of approximately 2,500 (QMF, 2011). The drag community were included in every major decision along the way and contributed not only their stories but also advice and support during the creative development process, but they were represented by three professional actors on stage, rather than performing themselves.

\section{Methods}

As befits the research aims, a humanist qualitative approach was considered the most appropriate for core data collection and analysis (Fossey et al., 2002). We took a reflexive approach to the project, examining our assumptions about power. We actively reflected on the researcher-participant relationship to co-constitute understanding and represent multiple voices, not just those who were dominant (Alvesson and Skoeldberg, 2000).

\section{Data collection}

To gain a holistic understanding of the culturally diverse concept of power at events, and as is common with qualitative research (Fossey et al., 2002), multiple methods were used to collect data. Individual semi-structured interviews were carried out with event organisers (Table 1), allowing some flexibility and scope to explore their ideas while still keeping the conversation on track (McGhee, 2012). The interviews, lasting between 43 and 97 minutes, were digitally recorded for later verbatim independent transcription. 
We wished to understand the perspective of a variety of event attendees, including volunteers, activity providers, stallholders, exhibitors, participants and audience members. They were approached in a considerate manner, so their experience was not unduly disturbed and, if willing to participate, were engaged in short in-the-moment interviews ranging from 4-10 minutes duration (Quinn and Wilks, 2013). In total, over 150 attendees participated in such conversations (Table 1). The only criteria were that participants were over the age of 18 for reasons of university ethics clearance. As noted by Fossey et al. (2002, p.726) "no fixed minimum number of participants is necessary to conduct sound qualitative research", and in this case the number of participants varied by event. This was determined by a combination of factors, the most important of which was the saturation point at which patterns were recurring and no new information was being gathered from the conversations (Fossey et al., 2002). Other less significant factors that influenced the number of participants recruited included the size, duration, physical layout and programming of the event. In order to minimise perceived researcher-participant power imbalance, the conversations were not audio recorded, but extensive notes were taken immediately afterwards to capture what was said.

Participants were asked about their experiences of the event, including why they decided to either organise it or attend it, what it means to them, how they feel about it, whether they feel the event is needed, and whether they believe it has made a difference to those who participate (and then what that difference might be). No questions explicitly addressed notions of power or empowerment; rather, we were interested in how these may arise and be referenced or alluded to during the conversations.

Overt participant observation was utilised at all events with permission from the event organisers: extensive notes and photographs were taken throughout each event to capture participant experiences, observations and rich descriptions of settings (Charmaz, 2006). Information gathered centred around attendee behaviour: what they were doing, where, with whom, what they were discussing, how they seemed to experience the event and interact (or not) with others and the event environment, what was happening in terms of event programming, the physical layout of the event and how attendees navigated it, and the sounds, smells and sights we (and attendees) were immersed in (Mackellar, 2013). These were later used as prompts during the semi-structured interviews with event organisers, as and when appropriate, to further explore our observations from different perspectives. Researcher reflections on this observational data were also captured at the time, as an early phase of the analysis process (Mackellar, 2013). Reflexive ethnography was only possible at the two 
Queensland Music Festival events, where the researcher was able to fully immerse herself in the event organisation in the months leading up to the events.

\section{Data analysis}

Thematic analysis was chosen for its flexibility and its ability to generate a rich and nuanced understanding of complex subjective social phenomena such as that under investigation here (Braun and Clarke, 2006). An inductive approach was employed to identify themes across all data sets - interview transcripts, in-the-moment interview notes, and field notes from participant observation and reflexive ethnography.

Thematic analysis is an iterative, nonlinear process involving the researchers going back and forth across the different phases of analysis (Braun and Clarke, 2006). In the first phase, the material was read to gain familiarity with the data and highlight words and phrases related to the notions of power and empowerment. Next, across repeated readings, initial codes (extracts of data) were identified and then consolidated into a series of basic themes based on their commonalities. Following this, these basic themes were then condensed over more phases of analysis, resulting in the identification of the eight higher-order themes presented in the findings. These eight themes were then checked for coherence and internal homogeneity by reviewing the codes and examples that comprised each theme (Braun and Clarke, 2006).

We worked both independently and collaboratively across the phases of analysis and across the different sets of data, as a form of investigator triangulation (Decrop, 2004). Each author took a reflexive approach in analysing their own collected data, while the other two acted as 'critical outsiders' discussing and assessing the insider's interpretation of the data and providing another perspective (Lofland et al., 2006).

\section{Findings and Discussion}

Eight themes around notions of power and empowerment were identified. Each will be unpacked in what follows, using excerpts from the data to illustrate them (all names have been changed).

\section{Platform}


For some groups, the events were seen as a platform, allowing them to have their voices heard or to showcase that which was important to them. The event organisers felt it was their job to provide this platform:

But [Auckland have] got the biggest Pacific community in the world ... and Wellington wants to be able to do something like [their festival]. Not on that scale, but for us, I think we need to be able to give them that platform so that we can celebrate our different dynamic communities that we have here and give them a showcase. (Pasifika Festival organiser)

Field notes also captured deliberate decision-making processes that allowed the community's voice to be showcased:

Jenny is joining us now and talks to Elizabeth about a particular scene that they might have to change a bit. Jenny points out that "we don't HAVE to change it, it's up to you, just let me know.” Again, I can sense this special relationship between them. Before making any changes to the script, Jenny and the others always check back with a member of the community. (Behind the Cane field notes)

This theme speaks to empowerment through engagement and participatory decision-making and indicates the potential of events to work at the top rungs of the ladder of citizen participation (Figure 1): delegated power is at work through the willingness and genuine efforts of the event organisers. It also links strongly to social-structural empowerment through the practice of participatory decision-making and the open flow of information between organisers and the communities they are working with (Spreitzer, 2008).

\section{Giving/taking ownership}

Event organisers recognised the need for the marginalised groups they were working with to feel ownership of the event, and genuinely strived to allow this:

I just think they feel it's their day, it's their chance to show off their area, and it's their...opportunity to participate as part of being a South Dunedin-ite (South Dunedin Street Festival organiser)

If the story is going to happen, the culture has to bubble out of the ground, it's got to be part of the culture here and that's got to inform everything: the story, the people who do it, the way it's told, all kind of has to bubble out of the community here. And for 
them to understand that it belongs to them and that we have a partnership. (Behind the Cane creative team)

We did that the whole way, like "what do you think of the script? What do you think of the music? Here is your story... it's been realised as a poetic piece of music, like a poem and music fusion. And this was a very tragic moment that happened to you, or a really dark thing that happened to you... What do you think of it? Do you want us to scrap it?"; So, there was always this sort of consultation of putting things in front of them and pulling it back. (Drag Queen'sLand organiser)

Again, this theme illustrates the importance of the social-structural dimension of empowerment, and here it contributes to the achievement of citizen control (the top rung on the participation ladder) (Arnstein, 1969; Spreitzer, 2008). Words such as 'participation' and 'consultation' are used but are more than tokenistic here: they reflect the deep-seated value systems of the event organisers, who seek to provide the support, information and resources needed for the communities to take ownership.

\section{Gaining confidence}

Event participants gained confidence through learning new skills, exhibiting their work, or performing in public:

There's a bunch of soft skills that people do gain confidence and competence in through doing this work... their posture changes, their eye contact changes, their speech may become clearer or more distinct or more particular. They learn to take turns; they learn to be socially appropriate. They learn [their] lines. (InterACT organiser)

I like the little dance group that you saw this morning, one of those little boys two months ago was so shy, he couldn't... And now look! Here they are, playing for the audience, confident... That's what it's all about! It's about offering people a chance to do something that's beyond what they believe they are capable of and us being at the bottom of the ladder when they fall and give them the strength to climb up again. (Behind the Cane organiser)

However, the events also provided inspiration for spectators and attendees to gain confidence to try something new as a result of seeing others succeeding: 
They [the seniors aerobics group] come every year... they are always the biggest hit, because, you know, people see them get up and they go, "I'm going to get up. If they can do it, I can do it”. (Pasifika Festival organiser)

There's a lot of men in business, you know, but when you're a woman at home on the farm in a rural area it's hard. This Expo might give them the kick they need, they might see all these women and think "Wow, I could do that too!" (Clutha Market and Trade Expo business exhibitor attendee)

These extracts illustrate the events' contribution to the psychological empowerment dimension of competence (Spreitzer, 2008) as well as to linking social capital (Taylor, 2011). Having their talents, skills and expertise valued and made visible gave the event participants confidence and gave event attendees a sense that if others could do it then so could they. Seeing others succeeding or trying something new is an important element of role modelling, particularly for marginalised communities, and this echoes other recent research that has identified events as a potential source of empowerment in this regard (Hassanli et al., 2019).

\section{Empowering with/through knowledge}

Knowledge, a contributing factor in social-structural empowerment (Spreitzer, 2008; Stadler, 2021) was disseminated through all events, and it was the communities themselves who were in control of that knowledge - and in control of the narratives about themselves:

My friends and other fellow students had no idea about the history of the South Sea Islanders, but when they saw this production, they now know and understand. The festival has not only touched the South Sea Islander community but also other nonSouth Sea Islanders (Behind the Cane attendee)

The cultural events in particular had an explicit focus on knowledge dissemination:

Diwali in Invercargill is a great event, especially for its ability to bring understanding/tolerance and get rid of racism through the next generation - school groups learn and perform Indian dances for the event, so it teaches the white/non-Indian kids about Indian and other cultures, and the adults that Indian culture is more than butter chicken. (Diwali audience attendee) 
Some knowledge that was imparted empowered the marginalised groups themselves, as it helped them understand and navigate the world around them, which could lead to better life outcomes:

By the time [the children] are about seven, most parents disconnect from disability support groups. But school doesn't actually tell them what to do next when school ends. So, knowing that, the other important thing is about saying, "Well if we can do this how do we tell other people it's possible?" That's really the purpose of the Festival. (InterACT organiser)

The event is worthwhile not only for recruiting Pasifika pharmacists and raising awareness of [our] organisation, but also for the conversations [we] have been able to have with event attendees about their health issues. So, it's good from a health education perspective as some may now choose to visit their doctor. (Pasifika Festival stallholder attendee)

Phipps (2010, p.230) identified similar empowerment through the dissemination of knowledge to "visitors from the outside" at two indigenous culture events in Australia and Hawaii. He noted the power of the learning and unlearning that happened for such attendees, and the transformative effects of this. Likewise, Stadler $(2013 ; 2021)$ found that events may play an important role in the creation of new knowledge for organisers, participants and the community alike and, in turn, their empowerment.

Again, this provides evidence of the potential for events to facilitate higher levels of community participation and therefore empowerment (Figure 1). The importance of linking social capital is also apparent (Taylor, 2011). Event organisers or others with power obtained through the lived experience of marginalisation shared their knowledge and network connections willingly. They recognised that they could empower others to navigate government or other bureaucracy because of their own first-hand experience and through developing their own community capacities.

\section{Respect}

Respecting event participants and attendees was important to the organisers as a fundamental human right - but one which was not generally accorded to the groups they were working with, in their everyday lives: 
And we respect each other, and then we celebrate the people who are more vulnerable among us are seen, who they're seen to be and what they're seen to do and how that's regarded. And if that's only for three days once a year, that's a good top up, that's a really good boost and reminder going forward. It's like filling your emotional bank account up for quite a long time - it takes ages to drain this stuff out again. (InterACT organiser)

...the other interesting thing about Bowen is, we tried to get this story about the history of the South Sea Island community into Townsville and Mackay. And both of those towns didn't want it. Whereas Bowen not only embraced it, but they actually gave the opening of the Soundshell, which was really big, and symbolic... so for the council to give that over to the South Sea Island community, is a reflection of the standing that the South Sea Island community have here in Bowen. It's special here in Bowen. (Behind the Cane local council representative)

We argue that respect, as demonstrated here, is one of the dimensions of psychological empowerment: it flows from adopting a truly community-focused, participatory and inclusive approach to event organisation that seeks to work in partnership with the community. This display of mutual trust is also evidence of bonding and linking social capital (Taylor, 2011; Wilks, 2011).

\section{Pride and affirmation}

Pride was clearly evidenced in participant observation field notes and in the interviews with event participants, attendees and organisers alike:

Definite pride and patriotism in the house when Punjabi women danced, the place went nuts! Lots of cheering and clapping. (Diwali field notes)

It lifts you up - if showing your culture makes you feel good, feel proud, it lifts you up inside. (Pasifika Festival activity provider attendee)

These quotes illustrate the presence of bonding social capital - the social cohesion and sense of celebration fostered by these events was manifest in this pride (Arcodia and Whitford, 2007).

At the InterACT Disability Arts Festival in particular, having their work or performance acknowledged was an affirmation of participants' ability, which stood in stark contrast with 
their everyday lives that were defined by their disability and mirrors Taylor's (2011) notion of capacity development:

So, I think it's just the thrill of the affirmation that you are an artist and that you have achieved a piece of artwork that is of an exhibitable quality...Because there's so little affirmation of your achievements when you've got a disability. You're seen mainly for that disability and not seen for your ability and the Festival celebrates people's abilities rather than their disabilities. (InterACT art exhibition organiser)

Event participants were therefore seen (by themselves, the event organisers, and us) to experience a strong sense of meaning, competence, sense of autonomy and impact as a result of the event - all psychological states that foster a sense of empowerment (Spreitzer, 2008).

\section{Freedom to 'be'}

For some participants, these events allowed them freedom from judgement, the freedom to be themselves:

The Festival means a lot to participants, it's a place they can come and not be judged, they can just be who they are, they are free. (InterACT volunteer attendee)

I'm from a small town and I'm a teacher and everyone knows me, you know, but here I can be ME and have a laugh. (Leisure Marching participant attendee)

Importantly, then, these events were temporary sites of power that provided participants and attendees alike with the autonomy to choose which activities to engage in, and to be able to do so with like-minded or like-bodied others.

\section{Resistance}

The final theme, but by no means the least important, was that of resistance. Almost all events allowed the marginalised groups to resist and to counter hegemonic discourses and stereotypes:

Not just the performances but their culture and arts and crafts and their people and their businesses, but also to a wider Wellington audience so that they can see what's actually happening with our Pacific people and to give them some positive stories as well, and share some of their role models that they have in the Pacific community with mainstream. (Pasifika Festival organiser) 
It's important that people realise that women can be in business, that we're just as capable - maybe even more capable! That we can paint, that we can wallpaper. (Clutha Market and Trade Expo business exhibitor attendee)

The inclusive approach adopted by event organisers meant a wide variety of people were able to participate as an exhibitor or stallholder, thus the events were a more accurate representation of the communities they sought to serve. This provided the communities with an opportunity to challenge hegemonic stereotypes, whether consciously or not, which supports Cole's (2006) and Vorobjovas-Pinta and Hardy's (2020) claims that events can be facilitators of empowerment through resistance, even if temporary in nature. This stands in contrast to Clarke and Jepson's (2011) work where the event organisers achieved hegemonic control over knowledge and participation, resulting in a lack of opportunity for minority groups to participate in a meaningful way.

\section{Theoretical framework for empowerment through events}

Bringing together the themes identified during the analysis with the elements of empowerment discussed in the wider literature, we have developed a theoretical framework that illustrates the process of empowerment through events (Figure 2).

\section{INSERT FIGURE 2 HERE}

Psychological empowerment can take the form of what Spreitzer (2008, p.67) refers to as "societal outcomes of empowerment." Within this study, these outcomes were identified as: consumption of the knowledge being produced and seeing the respect and pride of marginalised attendees. The positive flow-on aspects were increased understanding of the marginalised communities, which led to overcoming (negative) stereotyping, developing new friendships, and having confidence to speak out on behalf of marginalised communities.

Overall, the framework proposes that the four socio-structural elements of empowerment need to be in place pre-event (through the creation, design and organisation of the event) in order for the five psychological empowerment outcomes for event attendees to be realised, thus suggesting that empowerment is something that can be consciously created through events. We believe this framework will enable event organisers to both understand and deliberately plan for the productive use of power, which can reaffirm values and help them achieve important 
event aims and objectives. It also has potential to be a useful tool for researchers to evaluate the elements of empowerment at events.

\section{Conclusions}

Events for marginalised groups and communities often have empowerment as an objective, whether implicit or explicit, and it is thus important to understand how this may be achieved. In the past, however, research at the nexus of power and events has focused on the negative (Batty, 2016; Benfari et al., 1986; Clarke and Jepson, 2011). Our paper extends and reframes this understanding of power in an events context, in order to identify the processes that facilitate the empowerment of marginalised groups, and in so doing makes valuable theoretical and practical contributions.

\section{Theoretical implications}

Empowerment theory, which has traditionally been the domain of organisational and management studies (Buchanan and Badham, 2020; Conger and Kanungo, 1988; Spreitzer, 2008), is offered here as a new lens to explain how events may be used to empower marginalised groups and communities. This approach allows us to argue that empowerment through events is possible but requires an explicit focus on creating both social-structural and psychological dimensions of empowerment. However, the theoretical framework (Figure 2) also suggests that without attention being directed to the social-structural dimensions during the conceptualisation, planning and delivery of the event, it is unlikely that the psychological benefits of empowerment will be as strong (Spreitzer, 2008).

While some of the elements of our framework (e.g. providing a platform, giving ownership, making voices heard) have previously been explored in an events context (Arcodia and Whitford, 2007; Hassanli et al., 2019, 2020; Stadler, 2013; Vorobjovas-Pinta and Hardy, 2020; Walters, 2019), studies have focused predominantly on attendees, on a single element, and not specifically on empowerment. This paper is the first to provide a holistic understanding of the process of empowerment, and to provide evidence that psychological empowerment accrues not only to event attendees from marginalised groups, but also to volunteers, stallholders and organisers. As such, the framework contributes a new and more critical lens to reframe notions of power in event studies. 


\section{Practical implications}

This work also has value for event organisers, who can use our framework to both understand and deliberately plan for the productive use of power. As mentioned above, empowerment is often a goal of events held in, by or for marginalised groups. However, there may be uncertainty about how to go about planning for these beneficial outcomes, and what designing an 'empowering event' might look like in practice. Using the framework to guide event conceptualisation, design, development and delivery will help organisers focus their efforts and decision-making in ways that will maximise the opportunities for beneficial event outcomes for all attendees (participants, volunteers, stallholders, sponsors and others). It is argued that a better understanding of the interrelation between social-structural and psychological elements in the process of empowerment will allow event organisers to deliberately plan for these benefits, rather than simply waiting for them to occur as impacts. In addition, local government policy in many parts of the Western world is increasingly moving towards a discourse of community well-being: the framework may therefore be used to underpin policies and programmes that encourage organisers of public events (those funded and/or hosted by local councils) to create social benefit through events (Mair and Duffy, 2015). In this sense, events can be seen not only as a catalyst for the development of individual empowerment, but participation in events is also an important factor in capacity development and the enhancement of social capital at the organisational and community levels, and hence contributes to societal empowerment on a much broader scale.

\section{Limitations and future research}

Events research is not without its difficulties. In-the-moment interviews had to be carried out during gaps in the programming to avoid interrupting event attendees' experience, but even then, not all attendees were interested in chatting. At some events we encountered language/communication barriers, meaning we were not able to include all voices in the research. We also acknowledge the limitations of semi-structured interviews around the sensitive topic of marginalisation: the many 'positive' stories told by participants could have been shaped by the research relationship and by what event organisers deemed appropriate to say/not say. Lastly, the nature of qualitative research means the findings are specific to the groups and events in the study, and we make no claims of generalisability to the wider population. 
Moving forward, we encourage other researchers to apply and test the framework at events in other locations and for other groups and communities, and to refine it further. We also call for researchers to investigate the connections between different elements of the framework to provide deeper insight into empowerment at events. It would also be useful to identify examples of best practice for each of the socio-structural elements, which will add value for event organisers and local government event policymakers. To progress the practical contribution of this research, the next step is trialling the framework with event organisers, and modifying it based on their feedback. We also envisage developing the framework into an evaluation tool, with a series of indicators for each of the contributing factors, which will enable event organisers to measure their success in creating an event that empowers its stakeholders. This in turn will provide evidence of social outcomes that funders often require, hence extending the usefulness of the research for event practitioners.

\section{References}

Alvesson, M. and Skoeldberg, K. (2000), Reflexive methodology: new vistas for qualitative Research, SAGE Publications, London.

Arcodia, C. and Whitford, M. (2007), "Festival attendance and the development of social capital", Journal of Convention and Event Tourism, Vol. 8 No. 2, pp. 1-18.

Arnstein, S.R. (1969), “A ladder of citizen participation”, Journal of the American Institute of Planners, Vol. 35 No. 4, pp. 216-224.

Batty, R.J. (2016), “Understanding stakeholder status and legitimate power exertion within community sport events: a case study of the Christchurch (New Zealand) City to Surf", in Jepson, A. and Clarke, A. (Eds.), Managing and developing communities, festivals and events, Palgrave Macmillan, London, pp. 103-119.

Benfari, R.C., Wilkinson, H.E. and Orth, C.D. (1986), “The effective use of power”, Business Horizons, Vol. 29 No. 3, pp. 12-16.

Bock, B. (2016), "Rural marginalisation and the role of social innovation; a turn towards nexogenous development and rural reconnection," Sociologia Ruralis, Vol. 56 No. 4, pp. 552-573.

Braun, V. and V. Clarke. (2006), "Using thematic analysis in psychology", Qualitative Research in Psychology, Vol. 3 No. 2, pp. 77-101. 
Buchanan, D. and Badham, R. (2020), Power, politics, and organizational change, (3rd edition), SAGE Publications, London; Thousand Oaks, CA.

Charmaz, K. (2006). Constructing Grounded Theory - A practical guide through qualitative analysis, SAGE Publications, London; Thousand Oaks; New Delhi.

Clarke, A. and Jepson, A. (2011), "Power and hegemony within a community festival", International Journal of Event and Festival Management, Vol. 2 No. 1, pp. 7-19.

Cole, S. (2006), "Cultural tourism, community participation and empowerment", in Smith, M. and Robinson, M. (Eds.), Cultural tourism in a changing world - politics, participation and (re)presentation, Channel View Publications, Clevedon; Buffalo; Toronto, pp. 89-103.

Conger, J.A. and Kanungo, R.N. (1988), "The empowerment process: integrating theory and practice", Academy of Management Review, Vol. 13 No. 3, pp. 471-482.

Decrop, A. (2004), “Trustworthiness in qualitative tourism research", in Phillimore, J. and Goodson, L. (Eds.) Qualitative research in tourism, Routledge, London, pp. 156-169.

Fossey, E., Harvey, C., McDermott, F. and Davidson, L. (2002), "Understanding and evaluating qualitative research", Australian and New Zealand Journal of Psychiatry, Vol. 36 No. 6, pp. 717-732.

Foucault, M. (1980), Power/knowledge: selected interviews and other writings, Peregrine Books, London.

Foucault, M. (1982), “The subject and power”, Critical Inquiry, Vol. 8 No. 4, pp. 777-795.

Hassanli, N., Walters, T. and Friedmann, R. (2019), "Can cultural festivals function as counterspaces for migrants and refugees? The case of the New Beginnings Festival in Sydney", Leisure Studies, DOI: 10.1080/02614367.2019.1666296.

Hassanli, N., Walters, T. and Williamson, J. (2020), “'You feel you're not alone': How cultural festivals foster social sustainability through multiple psychological sense of community", Journal of Sustainable Tourism, DOI: 10.1080/09669582.2020.1797756.

Jepson, A. and Clarke, A. (2014), “The future power of decision making in community festivals", in Yeoman, I., Robertson, M., McMahon-Beattie, U., Backer, E. and Smith, K.A. (Eds.), The future of events and festivals, Routledge, Abingdon, pp. 67-83.

Jepson, A. and Clarke, A. (Eds.) (2018), Power, construction and meaning in festivals, Routledge, London; New York, NY. 
InterACTing Theatre Company (2019), "InterACT Festival”, available at: https://interacting.org.nz/interactfestival/ (accessed 3 February 2020).

Kauff, M., Wölfer, R. and Hewstone, M. (2017), “Impact of discrimination on health among adolescent immigrant minorities in Europe: the role of perceived discrimination by police and security personnel”, Journal of Social Issues, Vol. 37 No. 4, pp. 831-851.

Kay, A. (2000), "Art and community development: the role the arts have in regenerating communities", Community Development Journal, Vol. 35 No. 4, pp. 414-424.

Lawler, E.E. (1986), High Involvement Management, Jossey-Bass, San Francisco.

Leisure Marching New Zealand (2017), "History record", available at: http://www.leisuremarching.org.nz/history-record/ (accessed 3 February 2020).

Lofland, J., Snow, D., Anderson, L. and Lofland, L.H. (2006), Analyzing social settings - a guide to qualitative observation and analysis, Thomson Wadsworth, Belmont, CA.

Lukes, S. (1974), Power: a radical view, Macmillan, Basingstoke.

Macdonald, C. (2011), Strong, beautiful and modern: national fitness in Britain, New Zealand, Australia and Canada, 1935-1960, Bridget Williams Books, Wellington.

Mackellar, J. (2013), "Participant observation at events: theory, practice and potential", International Journal of Event and Festival Management, Vol. 4 No. 1, pp. 56-65.

Mair, J. and Duffy, M. (2015), "Community events and social justice in urban growth areas", Journal of Policy Research in Tourism, Leisure and Events, Vol. 7 No. 3, p. 282298.

McGehee, N.G. (2012), "Interview techniques”, in Dwyer, L., Gill, A. and Seetaram, N. (Eds.), Handbook of research methods in tourism: quantitative and qualitative approaches, Edward Elgar Publishing, Cheltenham, pp. 365-376.

Phipps, P. (2010), "Performances of power: indigenous cultural festivals as a globally engaged cultural strategy", Alternatives, Vol. 35, pp. 217-240.

QMF (2011), Queensland Music Festival program 2011, available at: https://issuu.com/queenslandmusicfestival/docs/qmf_final_print_23052011_final (accessed 31 July 2020).

Quinn, B. and Wilks, L. (2013), "Festival connections: people, place and social capital", in Richards, G., de Brito, M.P. and Wilks, L. (Eds.), Exploring the social impacts of events, Routledge, Abingdon, pp. 15-30. 
Reid, S. (2011), "Event stakeholder management: developing sustainable rural event practices", International Journal of Event and Festival Management, Vol. 2 No. 1, pp. 20-36.

Rogers, P. and Anastasiadou, C. (2011), “Community involvement in festivals: exploring ways of increasing local participation”, Event Management, Vol. 15 No. 4, pp. 387-399.

Satyanand, A. (2007), "Diwali Festival of Lights”, available at: https://gg.govt.nz/publications/diwali-festival-lights-0 (accessed 28 April 2020).

Siemens, L. (2010), “Challenges, responses and available resources: success in rural small businesses," Journal of Small Business and Entrepreneurship, Vol. 23 No. 1, pp. 65-80.

Smith, A. and Pitts, M. (2007), "Researching the margins: An introduction", in M. Pitts and A. Smith (eds) Researching the margins: strategies for ethical and rigorous research with marginalised communities. Palgrave Macmillan, Basingstoke, pp. 341.

Spreitzer, G.M. (1997), “Toward common ground in defining empowerment”, in R.W. Woodman and W.A. Pasmore (eds) Research in organizational change and development. JAI Press, Greenwich, CT, pp. 31-62.

Spreitzer, G.M. (2008), "Taking stock: a review of more than twenty years of research on empowerment at work", in Barling, J. and Cooper, C.L. (Eds.), The SAGE handbook of organizational behavior: Volume One: micro approaches, SAGE Publications, Los Angeles, CA; London; New Delhi; Singapore, pp. 54-72.

Stadler, R. (2013), "Power relations and the production of new knowledge within a Queensland Music Festival community cultural development project", Annals of Leisure Research, Vol. 16 No. 1, pp. 87-102.

Stadler, R. (2021), Knowledge Management in Event Organisations, Goodfellow Publishers, Oxford.

Stats NZ (1996), "Clutha District - census of population and dwellings 1996", available at: https://cdm20045.contentdm.oclc.org/digital/collection/p20045coll18/id/388 (accessed 29 April 2020).

Stats NZ (2013a), “2013 Census Quickstats about a place: Clutha District”, available at: http://archive.stats.govt.nz/Census/2013-census/profile-and-summaryreports/quickstats-about-aplace.aspx?request_value $=15096 \&$ parent $\mathrm{id}=14973 \&$ tabname $=\# 15096$ (accessed 29 April 2020). 
Stats NZ (2013b), “2013 Census QuickStats about a place: South Dunedin”, available at: http://archive.stats.govt.nz/Census/2013-census/profile-and-summaryreports/quickstats-about-a-place.aspx?url=/Census/2013-census/profile-andsummary-reports/quickstats-about-aplace. aspx\&request_value $=15068 \&$ tabname $=$ Work $($ accessed 25 March 2020). Stats NZ (2018), “2018 Census place summaries: Invercargill”, available at: https://www.stats.govt.nz/tools/2018-census-place-summaries/invercargill-city (accessed 29 April 2020).

Taylor, M. (2011), Public policy in the community (2nd ed.), Palgrave Macmillan, Basingstoke.

Tiew, F., Holmes, K. and de Bussy, N. (2015), “Tourism events and the nature of stakeholder power", Event Management, Vol. 19, pp. 525-541.

Vorobjovas-Pinta, O. and Hardy, A. (2020), "Resisting marginalisation and reconstituting space through LGBTQI+ events", Journal of Sustainable Tourism, DOI: $10.1080 / 09669582.2020 .1769638$

Walters, T. (2019), “'Proud to be South D': perceptions of a street festival in a marginalised community in New Zealand", in Walters, T. and Jepson, A.S. (Eds.) Marginalisation and events, Routledge, Abingdon, pp. 36-54.

Walters, T. and Jepson, A.S. (2019), “Understanding the nexus of marginalisation and events", in Walters, T. and Jepson, A.S. (Eds.), Marginalisation and Events, Routledge, Abingdon, pp. 1-16.

Wellington City Council (2019), "Wellington Pasifika Festival", available at: https://wellington.govt.nz/events/annual-events/summer-city/pasifika-festival (accessed 29 April 2020).

Westwood, S. (2002), Power and the social, Routledge, London.

White, Z. and Stadler, R. (2018), ““I don't think they give a monkey's about me” - exploring stakeholder power and community alienation at Glastonbury Festival”, in Jepson, A. and Clarke, A. (Eds.), Power, construction and meaning in festivals, Routledge, London; New York, NY, pp. 21-34.

Wilks, L. (2011), "Bridging and bonding: social capital at music festivals", Journal of Policy Research in Tourism, Leisure and Events, Vol. 3 No. 3, pp. 281-297. 


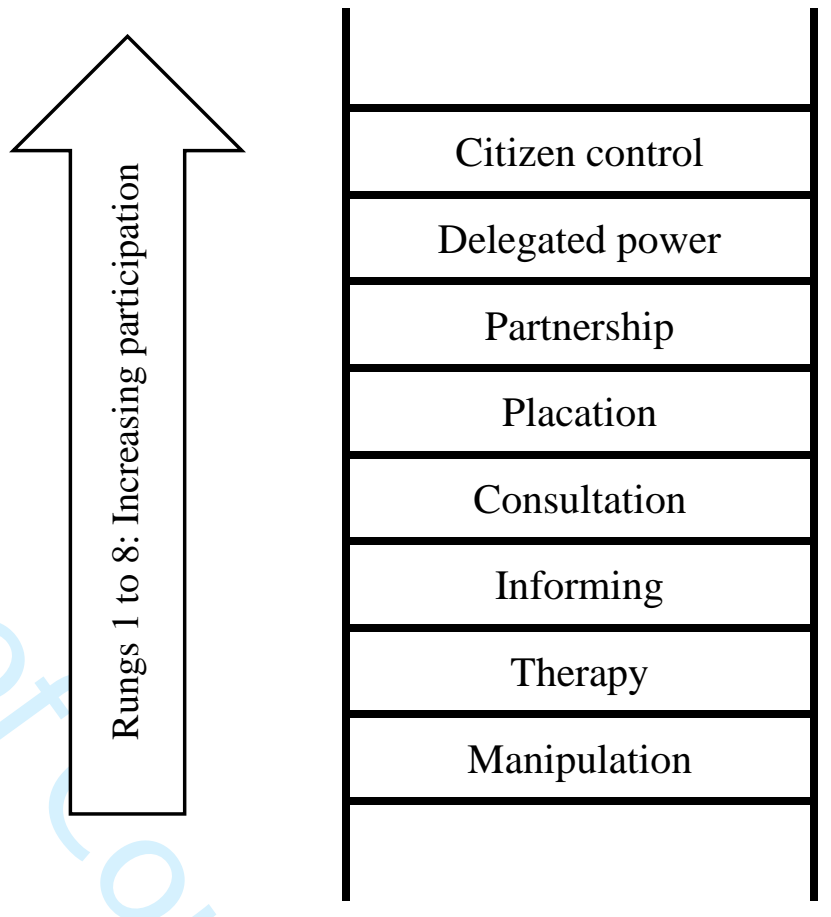

Figure 1: Ladder of citizen participation (Adapted from Arnstein, 1969). 


\begin{tabular}{|c|c|c|c|c|c|}
\hline Name of event & Location & Est. & Event organiser & $\begin{array}{l}\text { No. event organiser } \\
\text { semi-structured } \\
\text { interviews }\end{array}$ & $\begin{array}{l}\text { No. event attendee } \\
\text { in-the-moment } \\
\text { interviews }\end{array}$ \\
\hline Clutha Market and Trade Expo & New Zealand & 2017 & Clutha Women in Business Network & 1 & 12 \\
\hline Leisure Marching Nationals & New Zealand & 1991 & Individual host teams & 1 & 28 \\
\hline Pasifika Festival & New Zealand & 2006 & Wellington City Council & 1 & 11 \\
\hline Diwali Festival of Light & New Zealand & 2018 & Indian Community in Southland & 1 & 18 \\
\hline InterACT Disability Arts Festival & New Zealand & 2011 & InterACTing Trust & 2 & 17 \\
\hline South Dunedin Street Festival & New Zealand & 2011 & South D Street Festival Committee & 3 & 12 \\
\hline Behind the Cane & Australia & 2011 & $\begin{array}{l}\text { Queensland Music Festival and } \\
\text { Whitsunday Regional Council }\end{array}$ & 7 & 11 \\
\hline Drag Queen'sLand & Australia & 2011 & $\begin{array}{l}\text { Queensland Music Festival, The Judith } \\
\text { Wright Centre of Contemporary Arts } \\
\text { and Brisbane City Council }\end{array}$ & 3 & 6 \\
\hline
\end{tabular}

Table 1: Events selected for inclusion in the study. 


\section{Social - Structural Empowerment}

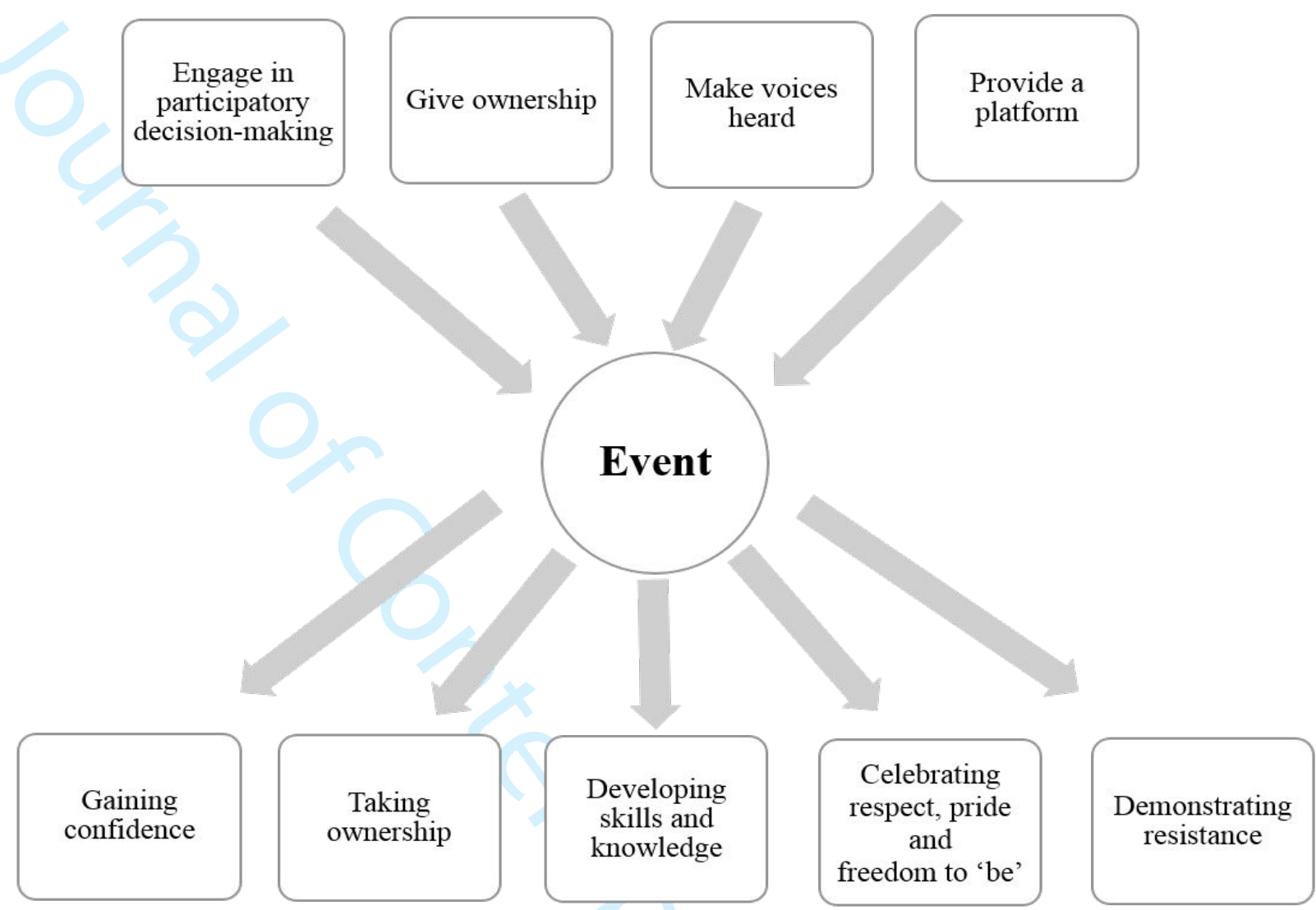

Psychological Empowerment

Figure 2: Theoretical framework for empowerment through events. 